\title{
A 'EXTRAVAGÂNCIA' DE TRABALHAR DOENTE: O CORPO NO TRABALHO EM INDIVÍDUOS COM DIAGNÓSTICO DE LER/DORT
}

\author{
THE 'EXTRAVAGANCE' OF WORKING SICK: THE BODY WORK \\ IN INDIVIDUALS DIAGNOSED WITH RSI/WRMD
}

\author{
LA 'EXTRAVAGANCIA' DE TRABAJAR ENFERMO: EL CUERPO EN EL \\ TRABAJO EN INDIVIDUOS CON DIAGNÓSTICO DE LER/EPO
}

\author{
Alana Pires Dale \\ Maria Dionísia do Amaral Dias²
}

Resumo Dentre as doenças do trabalho mais prevalentes estão as lesões por esforços repetitivos/distúrbios osteomusculares relacionados ao trabalho, as quais relacionam-se diretamente à organização do trabalho que ignora os limites do corpo e as singularidades dos trabalhadores. O objetivo deste artigo foi investigar os significados do corpo no trabalho em indivíduos com esse tipo de lesão/distúrbio. Para alcançar o objetivo proposto, fez-se um estudo de caso com abordagem qualitativa, a qual está embasada na teoria sócio-histórica da psicologia. Utilizaram-se entrevistas abertas individuais para coleta de dados, realizadas com nove participantes, os quais tinham diagnóstico de lesões por esforços repetitivos/ distúrbios osteomusculares relacionados ao trabalho e eram acompanhados no Centro de Referência em Saúde do Trabalhador de Botucatu (São Paulo). A análise dos dados revelou três núcleos de significação: necessidade de trabalhar - o corpo em movimento; submissão do corpo - falta de autonomia/poder; e corpo impedido - 'eu travei, eu parei minha vida'. Com base nesses núcleos foram identificados os significados e os elementos explicativos. O presenteísmo destacou-se entre os significados encontrados. A expressão que melhor define todo o processo saúde-doença dos participantes é 'a extravagância de trabalhar doente', e o produto deste é um futuro incerto.

Palavras-chave LER-DORT; significados do corpo; doenças profissionais; saúde do trabalhador; organização do trabalho.
Abstract Among the most prevalent occupational diseases are the Repetitive Strain Injury and WorkRelated Musculoskeletal Disorders (RSI/WRMD), which are directly related to the organization of the work that ignores the limits of the body and the uniqueness of each worker. The study main focus was to investigate the significance of the body at work in individuals diagnosed with lesion/disturb. To achieve the proposed objective, a case study was held in a qualitative approach, which is based in the socio-historical theory of psychology. The means used to achieve the data was through individual open interviews with nine subjects whom had been diagnosed with RSI/WRMD and were accompanied at the Worker's Health Reference Center in Botucatu (São Paulo, Brazil). As a result, three meaning cores have been revealed: need to work - the 'body' in motion; body submission - lack of autonomy/power; and prevented body - 'I caught, I stopped in my life'. In addition to these, meanings and explanatory material have composed the illustrator scheme of results of this research. The phrase that best defines the whole process of health/disease measured in the interviews according to the scenario reported by the individuals is 'The extravagance of working sick', and the product of this, is an uncertain future.

Keywords RSI-WRMD; significance of the body; occupational diseases; occupational health; work organization. 


\section{Introdução}

O modo de produção capitalista e sua reestruturação produtiva nos remetem à exploração do trabalhador pelo capital, com o objetivo de extrair o máximo do trabalho dos indivíduos desconsiderando as consequências de tais atos à saúde. A única fonte de subsistência para o trabalhador consiste na venda de sua força de trabalho em troca de salário, processo que acarreta a submissão, por parte dos trabalhadores, ao exercício de atividades perniciosas ao seu bem-estar.

Diante desse cenário, é necessário o desenvolvimento de investigações para melhor compreensão do problema relacionado ao adoecimento dos trabalhadores, de modo a lhe dar visibilidade e colaborar para propostas de mudanças que eliminem ou pelo menos minimizem os processos de sofrimento e adoecimento no trabalho. A pesquisa apresentada neste artigo objetivou investigar os significados do corpo para trabalhadores acometidos por lesões por esforços repetitivos/doenças osteoarticulares relacionadas ao trabalho (LER/DORT), utilizando a psicologia sócio-histórica como base teórico-metodológica. Essa teoria possibilita encontrar significados socialmente compartilhados entre os sujeitos da pesquisa, ou seja, dá a oportunidade de se aferir uma ideia comum entre os membros de um grupo, sociedade ou comunidade em determinado período de tempo na história. No caso do presente estudo, um grupo de trabalhadores portadores de LER/DORT.

Inicia-se o artigo com uma breve apresentação de alguns aspectos do trabalho e das LER/DORT que compõem o cenário da temática estudada e representam uma das principais patologias ocupacionais dos tempos contemporâneos.

\section{O trabalho e as LER/DORT}

O trabalho na sociedade capitalista tem características peculiares, que o distancia de sua origem de atividade humana fundamental, dadas as condições em que ocorre. Seu cumprimento deveria ser uma fonte de realização, desenvolvimento e conquistas pessoais e sociais, mas em contramão ao esperado, observam-se sentimentos de desprazer, sofrimento físico e psíquico, adoecimento e até mesmo a morte.

Algumas características observadas no mundo do trabalho são comuns a diversas atividades econômicas e ocupações, tornando-se elas em alguns momentos as responsáveis pelo adoecimento dos trabalhadores. Estudos (Assunção e Rocha, 1994; Brasil, 2001, 2012; Regis Filho, Michels e Sell, 2006) apontam elementos do trabalho ofensivos à saúde dos trabalhadores e suas consequências na vida deles, tais como os relacionados à organização do trabalho, além da exposição a riscos físicos, químicos, mecânicos e biológicos. 
Laurell e Noriega (1989) chamam esses elementos citados de 'cargas de trabalho', estas que atuam entre si e com o corpo do trabalhador, resultando em desgaste. Tal dano é compreendido como a perda da capacidade potencial ou física e psíquica dos sujeitos. Esse processo se refere à dinamicidade que há dentro da organização de trabalho.

O perfil epidemiológico do adoecimento dos trabalhadores vai se modificando historicamente conforme as mudanças ocorridas no mundo do trabalho e seu contexto socioeconômico. Estudos confirmam que os problemas de saúde ocasionados pelo trabalho se intensificaram com a introdução de novas tecnologias e métodos de organização do trabalho, no cenário do novo contexto de exploração do capitalismo (Brasil, 2001; Rosa et al., 2008; Pessoa, Cardia e Santos, 2010).

As LER/DORT representam hoje importantes evidências das condições de trabalho impostas a muitos trabalhadores de diversas ocupações. Essas patologias são reconhecidamente multicausais, a partir de um conjunto de fatores da situação de trabalho, atingindo, dimensões psicológicas, biológicas e sociais (Chiavegato Filho e Pereira Jr., 2004).

Como foi mencionado, a organização do trabalho é apontada como uma das principais responsáveis pelo grande número de trabalhadores com LER/DORT. Barbosa, Santos e Trezza (2007, p. 495) afirmam que estas são resultados “da superutilização do sistema osteomuscular, instalando-se progressivamente no trabalhador sujeito a fatores de risco técnico-organizacionais".

Tais patologias são caracterizadas como lesões em músculos, tendões, nervos, vasos, bainhas e outras estruturas responsáveis pela movimentação do corpo, que ocasionam dor no membro afetado, perda de força nos músculos e articulações, parestesias e fadiga, entre outros sintomas (Chiavegato Filho e Pereira Jr., 2004; Gaedke e Krug, 2008; Brasil, 2012). São ocasionadas por um conjunto de fatores inter-relacionados, tais como: exigência de força excessiva, postura forçada, repetição do mesmo movimento durante longo período, compressão mecânica, utilização de ferramentas vibratórias, postos de trabalho inadequados, ambientes com ruídos e mal iluminados, mobiliário inapropriado, pressão de tempo e cumprimento de metas de produção. Além de fatores da organização do trabalho: jornada prolongada, ausência de pausas periódicas e espontâneas, exigência de alta produtividade, ritmo intenso de trabalho, ambiente estressante, alta exigência de atenção para evitar erros, submissão a monitoramento permanente, entre outros. Suas consequências vão além da incapacidade profissional e trazem prejuízos à realização de atividades cotidianas (Assunção e Rocha, 1994; Brasil, 2001, 2012; Regis Filho, Michels e Sell, 2006).

O principal sintoma e fator limitante característico das LER/DORT são as dores, sobretudo nos casos de maior gravidade e com maior tempo de lesão. Há ainda outros fatores aferidos em estudos como ocasionadores de sofrimento 
aos trabalhadores portadores de tais lesões, como: limitação física, necessidade de adaptação para atividades de rotina; dependência de medicamentos; necessidade de afastamento do trabalho, provável mudança de função; medo de demissão; sentimento de inutilidade; vida cheia de incertezas e falta de perspectiva futura. Tudo isso é agravado pelo preconceito e discriminação da sociedade e até mesmo dos profissionais de saúde que os atendem, a partir do momento em que não é realizado o correto diagnóstico ou eles não acreditam na veracidade do que é relatado pelo paciente (Dias, 1995; Castelhano, 2005; Barbosa, Santos e Trezza, 2007; Gaedke e Krug, 2008).

\section{Abordagem teórico-metodológica}

Para alcançar o objetivo proposto foi realizado um estudo de caso, de abordagem qualitativa, embasado na teoria sócio-histórica da psicologia. Em tal abordagem teórico-metodológica, busca-se "apreender as mediações sociais constitutivas do sujeito, saindo assim da aparência, do imediato e indo em busca do processo, do não dito, do sentido" (Aguiar e Ozella, 2006, p. 225).

Nessa perspectiva teórica, a compreensão do fenômeno estudado buscou olhar e pensar a realidade em movimento, ou seja, como ocorreu o processo de adoecimento dos sujeitos e como tal fato teve influência na vida profissional e pessoal desses trabalhadores. A categoria de análise denominada significado permitiu apreender quais eram os elementos sociais compartilhados pelo grupo estudado em relação ao corpo no trabalho.

As significações sociais são as sínteses das práticas sociais conjuntas fixadas na forma de linguagem (Leontiev, 1978). O homem é resultado da assimilação de experiências das gerações precedentes, não necessariamente apenas de suas descobertas individuais, ou seja, passa por um processo de aquisição de significações chamado de conhecimento histórico acumulado, síntese de práticas sociais. A significação é conceituada como a generalização da realidade, que é a forma ideal, espiritual da cristalização da experiência e das práticas sociais da humanidade, pertencendo ao mundo dos fenômenos objetivamente históricos. Esse processo está sempre se modificando. Apesar de o indivíduo nascer num mundo de significados, deve se apropriar deles de forma singular (Leontiev, 1978).

A psicologia sócio-histórica nos dá a possibilidade de se trabalhar com informações presentes em determinadas sociedades e períodos históricos, fundamental para estudos relacionados ao mundo do trabalho, que se transforma e dinamiza com certa frequência (Aguiar e Ozella, 2006).

A pesquisa foi composta de dois momentos complementares. Em uma fase exploratória, buscou-se aproximação da pesquisadora com o problema de estudo na população que o vivenciava, de modo a conhecer o contexto em 
que os sujeitos pesquisados estavam inseridos - mediante a participação em atividades no Centro de Referência em Saúde do Trabalhador (Cerest) de Botucatu, São Paulo, e a realização de levantamento em prontuários de pacientes com diagnóstico de LER/DORT atendidos no serviço em 2012.

Realizou-se a pesquisa de campo propriamente com a participação de nove trabalhadores, entre 29 e 58 anos, com diagnóstico de LER/DORT, os quais foram convidados aleatoriamente entre pacientes em acompanhamento no Cerest de Botucatu. Foi utilizada a técnica de entrevista individual aberta para a coleta de dados, com o objetivo de conhecer alguns aspectos da vida pessoal, escolha profissional, dificuldades no exercício profissional, significações atribuídas ao adoecimento, significações atribuídas ao seu trabalho e à sua própria atuação, a relação do corpo no processo de trabalho, os significados a ele atribuídos, as perspectivas profissionais e projeto de vida. A análise dos dados foi conduzida conforme procedimentos propostos por Aguiar e Ozella (2006, 2013), e proposta de método de Vygotsky.

Este artigo é resultado da dissertação de mestrado intitulada Significados do corpo no trabalho em indivíduos com diagnóstico de LER, de autoria de Alana Pires Dale (2015). Todos os procedimentos de investigação foram iniciados após aprovação do Comitê de Ética em Pesquisa da Faculdade de Medicina de Botucatu/Universidade Estadual Paulista (Unesp), com parecer número 381.006.

\section{Necessidade, submissão e impedimento: significados de corpo para os sujeitos da pesquisa}

O grupo de trabalhadores participantes da pesquisa exerciam atividades diversas como: operadora de caixa de supermercado (Márcia); ajudante de pedreiro (Pedro); plantio de eucalipto (Kelly); operador de jato de areia (Rogério); auxiliar de serviços gerais (Helena); operador de prensa excêntrica (Paulo); auxiliar de limpeza (Maria); colhedora de laranja (Sara); e auxiliar contábil (Catarina). Dentre estes trabalhadores, apenas um permanecia exercendo sua atividade profissional no período em que foram realizadas as entrevistas; os outros encontravam-se afastados do trabalho para tratamento de saúde. Os nomes citados são fictícios e foram escolhidos pelos próprios trabalhadores.

O grupo de participantes da pesquisa quanto ao perfil de inserção em setores de atividade econômica condiz com o apontado na literatura, que destaca o constante crescimento do setor de serviço e da introdução de mulheres nessa esfera (Antunes, 2015).

Os resultados da análise do conjunto das entrevistas foram sintetizados em três núcleos de significação, compostos por um conjunto de significados e elementos explicativos que se inter-relacionam - necessidade de trabalhar: 
o corpo em movimento permanente; submissão do corpo: falta de autonomia/ poder; corpo impedido: 'eu travei, eu parei minha vida'.

\section{Necessidade de trabalhar: o corpo em movimento permanente}

Este núcleo trata dos motivos da submissão dos sujeitos ao trabalho precário. Captaram-se nas entrevistas duas necessidades diferentes que justificavam a permanência dos sujeitos no trabalho, mesmo ele sendo adoecedor. Uma delas foi a 'necessidade de subsistência', essencial para a sobrevivência do ser humano, que na sociedade capitalista é garantida pelas relações de trabalho remunerado, ou seja, o emprego - como exemplificam as falas de Maria e de Helena:

Foi necessidade mesmo. (...) É, mas como eu estava precisando, cê vê, no ano que eu entrei lá, meu marido morreu, então a responsabilidade caiu o drobo na minha cabeça, então eu tinha que trabaiá de qualquer maneira, ganhando pouco ou muito, tinha que tá ali, né? (Maria).

(...) assim a gente trabalhava por necessidade mesmo do trabalho, eu sempre gostei de trabalhar, nunca fui de ficar em casa, eu comecei a trabalhar com sete anos de idade, meu pai morreu eu tinha seis anos, né? Então eu fui morar com outra família (Helena).

Outra necessidade verificada foi a 'psicossocial', de produzir e criar algo que lhes proporcionasse sentimentos como o de ser útil, realizado e valorizado pelo que faz.

Que na verdade mesmo eu queria é fazer o tratamento, né? Que eu pudesse assim curar, pra mim eu preferia trabalhar, a minha alegria é trabalhar (Sara).

Os entrevistados, ao expressarem suas ideias e vivências com o trabalho, confirmaram a teoria de que toda atividade é realizada para suprir alguma necessidade, como afirma Leontiev (1978). Mas na sociedade capitalista o trabalho perde muitas vezes sua essência de realização no e pelo trabalho, restringindo-se a ser unicamente fonte de sustento do trabalhador (Antunes, 2015).

Moulin, Reis e Wenichi(2001) expõem aspectos que corroboram o que foi relatado pelos sujeitos da pesquisa, quando afirmam que o ato de trabalhar representa o sustento e a sobrevivência do sujeito e de sua família, expressando garantia de vida e dignidade, necessária mesmo quando há a presença de riscos à saúde. Além da ideia de apenas suprir necessidades materiais, há 
a satisfação em realizar atividades, produzir algo, ser útil, ou pertencer a uma categoria na sociedade, a de trabalhador. Souza e Faiman (2007) acrescentam a satisfação em ser reconhecido por um feito realizado com sucesso, pela competência no trabalho, por ser visto como um consumidor em potencial, além de ser considerado dentro de círculo social e familiar.

$\mathrm{O}$ risco de perder a fonte que supre as necessidades de tais trabalhadores faz com que estes busquem ou aceitem qualquer tipo de trabalho (Antunes, 2015).

\section{Submissão do corpo: falta de autonomia/poder}

No mundo da produção capitalista, a submissão do corpo ao trabalho precarizado é constantemente observada - os fatores motivacionais para que tal prática ocorra são diversos, como já assinalado. Não diferente de outros trabalhadores, os participantes da pesquisa também faziam parte dessa sociedade sujeitada. Nesse núcleo, emergiram significados que caracterizavam o trabalho dos entrevistados e suas consequências.

Uma característica marcante do mundo do trabalho capitalista é a perda do poder sobre o seu próprio corpo, deixando o trabalhador de ter autonomia sobre o que muitas vezes é seu único instrumento para o trabalho. E essa falta de controle sobre como, quando e quanto realizar as atividades pode ser muito danosa à saúde dos indivíduos. Alves (2013, p. 128) afirma a esse respeito: "O homem que trabalha perde o controle de seu corpo e de sua mente - e por conseguinte de sua doença". O controle excessivo sobre os trabalhadores os impede de tomar decisões nas suas atividades, de se expressarem, além de limitar a sua liberdade de movimento, acarretando assim o adoecimento físico ou psíquico (Souza e Faiman, 2007). Em certas formas de trabalho, como no setor de serviços, a apropriação é também das emoções dos trabalhadores e não somente de sua capacidade física e cognitiva (Pena e Minayo-Gomez, 2010).Desse núcleo emergiram três significados: trabalho 'castigado'; presenteísmo; e autoculpabilização - os quais estão relacionados a quatro elementos explicativos de base: a 'naturalização do trabalho desgastante', o 'valor moral do trabalho', a 'baixa escolaridade' e o 'envelhecimento precoce'.

Quando em uma sociedade o indivíduo não é detentor do capital, dos meios nem da matéria-prima para a produção de bens, ele vê como única alternativa de manter seu sustento a venda de sua força de trabalho, na qual ele é submetido a atividades que muitas vezes retiram seu poder de decisão, ferindo a singularidade e sua capacidade de criação. Um trabalho no qual o sujeito não tem autonomia nem pode expressar sua criatividade acaba perdendo seu sentido e exprime apenas o significado social dado a ele, utilizando apenas sínteses dessas práticas sociais. Contudo, tais métodos podem não estar em 
conformidade com a singularidade dos sujeitos, o que faz com que estranhem a execução de suas atividades e se tenha como resultado a alienação em relação ao processo de produção em que cada um está inserido (Leontiev, 1978).

Como assinalado, um dos significados que surgiram demonstrou como era o trabalho a que os entrevistados se submetiam, sendo ele denominado como 'castigado', adoecedor, por apresentar diversas características que acarretavam sofrimentos diversos e possíveis fatores responsáveis pelo adoecimento deles, de modo a ocasionar para a maioria o afastamento de suas atividades.

Com base nos relatos dos sujeitos, foi possível observar a multiplicidade de fatores que podem ocasionar as LER/DORT, como falhas na organização do trabalho e gestão, cargas físicas excessivas, ambiente físico inapropriado, inadequação de materiais. Kelly e Márcia apontaram mais alguns. 'Castigado', 'sofrido', desgastante foram algumas características do trabalho trazidas pelos entrevistados.

Cortá mudinha eu cortava bem, eu gosto de cortá mudinha, prantá, eu não gostava muito de prantá, não, prantava mais não gostava, não, quer dizer, não gosto [risos], não gosto! Agora, limpar eu gosto, limpar as mudinha, mais é um serviço bem castigado tamém (Kelly).

É, muito quente, a gente tem aqueles guarda-sol, ele dava pra gente, aquilo ali mais não impede muito, não. Então lá é muito sofrido (Kelly).

Ah, tem muita coisa assim, eu acho que era a rotina desgastante, a diária, né? De segunda a domingo, é... tinha poucas folgas, tinha que tá repetindo o movimento sempre, eram oito horas por dia, tá repetindo o mesmo movimento, né? Eu acho que isso que era o mais cansativo, cansava o corpo e a mente também ali, né? Que tinha que ficar lidando com cliente o dia inteiro, então estressava bastante (Márcia).

Tais características presentes no trabalho se "desenvolvem histórica e socialmente decorrentes do crescimento econômico e da diversificação dos processos produtivos" (Oliveira e Mendes, 2014, p. 4.628) e de interesses político-ideológicos. Oliveira e Mendes (2014) ainda ressaltam que tal caracterização pode ser explicada pela existência de falhas propositais nas condições de trabalho que adicionam riscos à saúde do trabalhador, como aqueles associados ao ritmo de trabalho, ausência de pausas periódicas e jornadas prolongadas, entre outros.

Essas características são muito presentes no mundo do trabalho capitalista, no qual se explora ao máximo a mão de obra do trabalhador, sem nem mesmo lhes dar subsídios necessários para cumprir suas atividades de forma adequada e confortável. Mesmo os trabalhos com menor exigência de esforço 
físico podem levar ao desenvolvimento de LER/DORT, como exemplificado pela auxiliar contábil, que apontou inconformidade em seu ambiente de trabalho, como falta de mobiliário adequado, o qual não condiz com suas medidas antropométricas e dificulta assim a correta realização de sua atividade - o que pode, em conjunto com aspectos dos modos de organização e gestão do trabalho, em muitos casos acarretar problemas posturais e de movimentação.

Soares (2013) acrescenta que os trabalhadores realizam suas tarefas de acordo com o exigido, mesmo que isso lhe custe viver durante um período ou permanentemente com dor, sendo este um fator limitante em relação à movimentação de membros ou, em muitos casos, impeditivo para tarefas da vida como um todo.

Em estudo realizado com trabalhadores de um escritório de contabilidade, constataram-se alguns elementos que reforçam essa discussão como aspectos negativos da atividade laboral: pressão de chefe e clientes, sobrecarga de trabalho, ritmo acelerado para cumprimento de metas, o que resultava em estresse e desgaste (Eufrasio, 2014). O trabalho com essas características relaciona-se em mão dupla, ou seja, como causa e consequência, com um elemento destacado nas entrevistas: o 'envelhecimento precoce'. Este aspecto foi ressaltado principalmente pela entrevistada de 36 anos que trabalhava com colheita de laranja, a qual relatou como importante consequência ocasionada pela sua rotina de trabalho o 'envelhecimento precoce', deixando transparecer como um trabalho insalubre interferia na vida das pessoas e fazia com que um sujeito jovem se sentisse mais velho em decorrência do desgaste gerado pelo trabalho.

(...) você vai deixando, ah, passa um... aí você vai deixando, você vai trabalhando, depois com o passar dos anos que você vê, mas enquanto isso não, é verdade, enquanto isso você não vê, quando você é nova, você faz cada extravagância, não é uma dorzinha só, ah, não vou ao médico, passar, aí vai, vai acumulando, aí depois é complicado (Sara).

Esse relato corrobora o estudo de Rocha e Felli (2004), que acrescenta a ameaça à estabilidade no emprego ocasionada pela diminuição da produtividade.

$\mathrm{O}$ 'presenteísmo', expressão que vem sendo utilizada na literatura da área de saúde do trabalhador (Franco, Druck e Seligmann-Silva, 2010; Araújo, 2012; Garrow, 2016), se caracteriza pela permanência do trabalhador adoecido em suas atividades de trabalho. Tal situação foi referida pelos entrevistados e pode ser relacionada a alguns motivos: a necessidade de um salário, a falta de oportunidades em outras áreas, o sentimento de responsabilidade e de ter que cumprir bem sua atividade e a naturalização das más condições de trabalho.

Porque eu sempre tinha algumas dores era na... no braço, no pulso ou no pescoço, mas a gente tomava um remédio e passava. (...) Eu tava trabalhando, eu 
fiquei na época um mês, um mês e meio trabalhando com a dor, com o problema da dor (Márcia).

(...) aí tive um problema de LER mais leve, sabe? Não teve rompimento, não teve nada e eu não me afastei, continuei trabalhando (Paulo).

Para se manterem trabalhando, apesar de adoecidos, os trabalhadores buscavam estratégias que visavam a tornar menos penosa a situação imediata, entretanto essa atitude poderia contribuir para o agravamento da lesão. Alguns utilizavam táticas como a mudança do modo de execução da atividade, a utilização de acessórios para estabilização do membro afetado, a ingestão de medicamentos, entre outros meios para amenizar seu sofrimento. A permanência de um sujeito lesionado no trabalho, além do agravamento da lesão, ocasiona o declive da sua produtividade (Garrow, 2016), o que coloca em xeque a estabilidade dele no emprego.

A alta ocorrência do 'presenteísmo' pode estar relacionada ao aumento do desemprego na atualidade, o que força os indivíduos que estão no mercado de trabalho a se sacrificarem para permanecerem dentro dele, muitas vezes escondendo o próprio adoecimento para se manterem em atividade (Araújo, 2009). Em estudo desenvolvido por Iriart e colaboradores (2008), esse fenômeno foi observado quando os trabalhadores continuavam executando suas atividades mesmo após o acidente ocorrido, além de não receberem nenhum tipo de apoio ou ajuda de seus superiores.

Já o significado 'autoculpabilização' apresenta relação com a naturalização de se exercer um trabalho desgastante, em condições inadequadas, pois é nesse momento que ocorrem a aceitação de exercer uma atividade laboral danosa à saúde e a conformidade de que os próprios trabalhadores devem se prevenir dos riscos.

Os participantes não por vezes demonstraram não reconhecimento da sua atividade laboral como principal ocasionador de seu adoecimento, e sim atribuíam a si mesmos a responsabilidade sobre a situação, por falta de autocuidado e a forma como realizavam o trabalho, como exemplificam as falas de Pedro e Márcia:

(...) quando eu tava trabaiando, se eu tô... e encho um carrinho de areia ou de tijolo ou de pedra que seja, tem vez que eu dou três passos, coluna já ameaça. Quantas vezes eu larguei serviço, e falei com o encarregado aqui perto que faz massa, correr na farmácia comprar remédio, aí naquilo a coluna vai uns par [sic] de dias, eu me aleijei, e fico até quando a coluna melhora, aí fica bom dois, três dia, aí quarquer coisinha, e talvez até no deitar (Pedro). 
(...) eu também acabei na minha parte não fazendo, eu era muito acomodada, então eu só trabalhava, não saía do meu serviço e ia procurar uma ginástica, um exercício físico, era uma coisa pra minha prevenção, né? Era uma coisa que eu não, não tava me prevenindo, eu só trabalhava, não fazia nem alongamento no caixa (Márcia).

Esse aspecto também foi evidenciado quando havia comparação entre colegas de trabalho no sentido de que alguns adoeciam e outros não, mesmo exercendo as mesmas atividades, durante o mesmo período de tempo, o que ocorre em decorrência de fatores organizacionais do trabalho e individuais dos trabalhadores, como aspectos biológicos e psicossociais (Silva et al., 2013). Esses quadros trazem sofrimento às pessoas. É uma situação em que elas não têm controle e sofrem com a falta de respeito em relação aos limites e diferenças físicas e psíquicas por parte da organização do trabalho (Neves, 2006).

Tal fato foi constatado também na pesquisa de Iriart e colaboradores (2008) com trabalhadores do setor de limpeza e da construção civil, em que os sujeitos se sentiam culpados pelos acidentes e doenças ocupacionais, julgando como os responsáveis a desatenção, o descuido e a displicência deles.

Dessa forma, observou-se como a alienação estava presente nesses sujeitos que não tinham consciência do principal responsável pelo seu adoecimento, ao entrar em consonância com o que Leontiev (1978) e Heller (1985) apontam como a falta de conscientização dos sujeitos em relação aos fatores que compõem suas atividades.

Nos relatos dos sujeitos, a penosidade e as cargas de trabalho que realizavam foram indicadas como naturais, como se fosse inerente ao trabalho ser pesado e danoso à saúde. A baixa escolaridade pode ter contribuído para essa concepção, ao dificultar a realização de outros tipos de atividades, encontrando barreiras ainda maiores nos locais de trabalho onde se adota o modelo de produção flexível, os quais buscam profissionais com maior grau de qualificação profissional e intelectual (Antunes, 2015; Alves, 2013). Além disso, no momento em que um adulto perde seu emprego, ter o grau de escolaridade baixo se torna um grande problema, o que dificulta seu retorno ao mercado de trabalho e faz com que muitos optem por atividades informais (Pero, 2010).

$\mathrm{O}$ ingresso precoce no mercado de trabalho e a falta de experiência em outras áreas reforçam ainda mais essa 'naturalização do trabalho desgastante'. Em estudo sobre a precarização do trabalho afirma-se que, para os sujeitos, o adoecimento é um evento normal, já esperado pelo trabalhador (Takahashi et al., 2012). Outro aspecto que reforça esse raciocínio é quando a atividade profissional apresenta similaridade com a atividade desenvolvida na vida particular dos trabalhadores (Iriart et al., 2008). A trabalhadora Sara, quando disse que o trabalho era bom, apesar de ela ter adoecido, exemplificou tal fato em seu relato: 
Apesar de que ali onde eu tô eles não me incomodam, a fazenda era bom porque era tranquilo também, né? Saía cedo, ficava no meio do mato o dia inteiro, o que eu saí da fazenda foi por causa do menino mesmo, não tinha quem ficasse com ele, senão tava lá até hoje, eles queriam que eu ficasse lá, né? Eu saí por causa do menino (Sara).

O 'valor moral' revela um pouco sobre o modo de ser desses trabalhadores participantes, característica pessoal que pode explicar em parte a submissão do corpo e o presenteísmo vivenciado por eles. Para os trabalhadores, o dever de cumprir o trabalho de forma adequada é de extrema importância, em razão do salário que está recebendo ou do sentimento de realizar um bom trabalho e ser reconhecido por tal feito. Esse valor contribui para que mesmo adoecidos continuem trabalhando, comprometendo ainda mais a sua saúde. Foi o que aconteceu com Sara, que mesmo com autorização de deixar algumas tarefas do trabalho por fazer, fez questão de realizá-las, apesar do adoecimento.

É, eu vou no meu ritmo, que ela fala 'deixa aí', mas não é certo, né? O que é certo é certo, então, mas antes de afetar muito mesmo, três e meia, às vezes duas e meia, tava indo embora, naquele horário mesmo, mas agora... (Sara).

\section{Corpo impedido: 'eu travei, eu parei minha vida'}

Este núcleo contém as causas e consequências atribuídas às condições de trabalho e ao adoecimento físico e mental dos sujeitos. Na sociedade atual, ter o corpo adoecido e consequentemente impedido para o trabalho e para a vida é sinônimo de mudanças em vários aspectos na vida pessoal e profissional dos indivíduos.

No caso da pesquisa aqui apresentada, o corpo impedido é consequência das LER/DORT e pode ser causador de 'dificuldades emocionais' e 'dificuldades de realizar outros trabalhos', esta última agravada pela 'baixa escolaridade'. As LER/DORT são patologias multicausais, por esse motivo pode-se observálas em profissões diversas como verificado no estudo, cada pessoa com sua lesão em local específico de acordo com a atividade que realiza.

Os entrevistados apresentavam seu adoecimento por meio de seus sintomas, como perda de força, parestesia e inchaço, mas também pela característica comum a todos eles: dor nos membros afetados, ocasionada principalmente por rompimentos de tendão, inflamações em nervos e músculos, por exemplo. São características que corroboram os resultados de estudos sobre essas lesões, conforme já mencionado (Chiavegato Filho e Pereira Junior, 2004; Gaedke e Krug, 2008; Brasil, 2012). 
Exatamente, eu tive que acelerar tudo, porque assim, no prazo de duas semanas, eu fiz 150 declarações. Então foi assim, eu terminei as declarações, quando chegou no final de semana, eu não... eu acordei, eu não consegui mexer braço e nem pescoço (Catarina).

Catarina trouxe na sua fala uma das causas e consequências acarretadas pela sua atividade. Já Pedro citou a dificuldade para dormir por causa da lesão:

O braço é tendinite. (...) Isso aqui trava, aí pra ele vortá tenho que trazer e estrala, não pode deitar desse lado, eu deito um pouco desse e tenho que virar, daí quando eu consigo dormir, tá formigando as mão, dá vontade até de chorar, que isso dói (Pedro).

Em todas as entrevistas foram ressaltadas consequências ocasionadas pelas patologias que compõem as LER/DORT, como dores no corpo, dificuldades para realizar o trabalho, dificuldades na vida cotidiana, ocasionando adaptações e mudanças, além de necessidade do auxílio de outros para cumprir determinadas tarefas. Alguns dos resultados dessas limitações trazidas pelos entrevistados foram: demissão, afastamento do trabalho e aposentadoria precoce por invalidez.

Quando se observou que o trabalho chega ao ponto de impedir o sujeito de realizar qualquer atividade, nos veio a ideia de que há algo errado no modo como as atividades estão organizadas. A ambição faz crescer o desrespeito com os trabalhadores, que passam a se tornar apenas parte da produção, sujeitos sem identidades, que estão ali apenas para produzir bens.

Conforme mencionado, as LER/DORT não trazem prejuízos apenas ao corpo do trabalhador, mas também ao seu lado psicológico, uma vez que um não existe sem o outro, portanto tais implicações atingem o sujeito como um todo. Sznelwar e Masseti (2002) exemplificam atividades simples do cotidiano que um trabalhador adoecido passa a ter dificuldade de realizar, como pentear os cabelos, lavar a louça, carregar seu filho no colo, o que também foi relatado pelos entrevistados da pesquisa aqui apresentada.

Braga e colaboradores (2013), em estudo com operadores de caixa de supermercado, corroboram o que aqui já foi apresentado, ao observarem diversas consequências negativas do trabalho sobre a saúde dos trabalhadores, sendo estas físicas ou psíquicas, como fadiga, dor nos músculos do pescoço e ombro, dor de cabeça, dor de estômago, excesso de fome, ansiedade, nervosismo, irritabilidade, angústia, alteração de humor e depressão.

A expressão 'dificuldades emocionais' refere-se ao sofrimento dos trabalhadores durante a permanência no trabalho ou após o afastamento, ocasionado principalmente por incertezas em relação ao futuro dentro do trabalho, pressão sofrida por parte de superiores, dificuldades diversas depois do afastamento, 
entre outros fatores. E isso foi trazido por vários dos sujeitos entrevistados, dentre eles a trabalhadora Helena:

(...) assim, muita pressão, a cobrança, você acaba tipo torturando [sic], você fica... dá sistema nervoso nocê, aí o que me causou, começou a me dar vômito, diarreia, mais ou menos uns sessenta dias assim (Helena).

Neves (2006) cita alguns desses problemas que apresentam consonância com o observado, como o sentimento de desgaste, invalidez, além de angústia e depressão. No estudo realizado por Torres e colaboradores (2011), o adoecimento profissional veio acompanhado de importantes consequências: dor, limitações funcionais, pressão psicoemocional, que ocasionam mudanças importantes na vida dos trabalhadores afetados.

Para muitos dos participantes da pesquisa, a possibilidade de realizar outras funções que não a de trabalhos manuais desgastantes, como a que exerciam anteriormente, era desconsiderada por eles não possuírem um nível de escolarização suficiente para a mudança de atividade. Por esse motivo permaneciam no mesmo trabalho, ou atuavam em outras atividades com riscos semelhantes.

Já não tem estudo, estudei muito pouco, outra coisa não sei fazer (Pedro).

Agora é meio complicado, né? Porque... eu não tenho estudo, como que eu vou mudar, né? Não tem como (Sara).

Quando refletimos sobre o corpo em trabalhadores com adoecimentos ocasionados pela atividade laboral, observam-se sujeitos que têm necessidades, com corpos submissos, e que apresentam limitações. Tudo isso traz a eles consequências imediatas, mas também um 'futuro cheio de incertezas', principalmente sobre voltar a exercer as mesmas atividades ou, em caso negativo, qual trabalho possível a ser exercido por eles. Em alguns casos, as sequelas do adoecimento são fortes barreiras que limitam o retorno ao trabalho (Souza e Faiman, 2007).

(...) olha, eu tô de jeito que eu não, não sei mais o que é que eu faço, eu tenho que levar agora até onde Deus der (Pedro).

Assim, perto do que eu tava, assim eu sinto melhora, mais o dia assim que às vezes fico um pouco nervosa, assim por essa situação que eu não sei o que vai acontecer, né? Se vou ter alta ou não. Então eu sinto que isso acarreta com que eu fique com mais dor, por eu tá tensa, né? (Catarina). 
Dias (1995) e Gaedke e Krug (2008) trazem outros fatores ligados às incertezas em relação ao futuro, tais como provável mudança de função, medo de demissão e falta de perspectiva futura. Outra situação ocasionadora de intensa ansiedade ocorre no momento do retorno ao trabalho após o afastamento por doença, principalmente em relação ao seu restabelecimento, ou seja, se a pessoa conseguirá cumprir as atividades assim como antes do adoecimento (Souza e Faiman, 2007).

\section{Considerações finais}

Os resultados da pesquisa aqui apresentada procuraram demonstrar a dinâmica do processo de adoecimento dos trabalhadores e as consequências no trabalho e na vida cotidiana. Seu produto se aproximou muito de resultados de outros estudos relacionados às LER/DORT e sua relação com o trabalho. Acredita-se que isso ocorreu, pois o modo de organização capitalista do trabalho abrange todos os setores e atividades econômicas, de formas diversas, mas com consequências semelhantes.

Dentre todos os significados encontrados, destacou-se o presenteísmo, pela sua relação com os outros elementos e com os três núcleos de significação, bem como pela referência em todas as entrevistas. Tal fato reforça a necessidade de constantes discussões e organização de estratégias para melhorias em relação ao processo trabalho/saúde do trabalhador por parte de pesquisadores, empregadores e profissionais da saúde, os quais devem dar a devida atenção aos trabalhadores que, mesmo adoecidos, fazem a 'extravagância' de continuar trabalhando, comprometendo ainda mais sua saúde.

Ainda em relação com o presenteísmo, a 'extravagância de trabalhar doente' foi compreendida como uma expressão que traduzia de forma ampla e completa o processo de trabalho/adoecimento dos trabalhadores entrevistados. A atitude que os trabalhadores tomavam em relação a sua atividade, ou seja, continuar realizando seu trabalho mesmo doentes e com dor, não revelava uma escolha, mas sim uma condição de vida dessas pessoas, na qual a sobrevivência ainda se destaca como necessidade primeira. Diferentemente do que podemos observar em outros grupos da sociedade atual, em que as extravagâncias muitas vezes estão relacionadas ao consumo excessivo, ao qual todos somos induzidos, principalmente de bens não essenciais - o que evidencia, assim, a diversidade de classes que compõem a sociedade, com desigualdade nos acessos a bens e benefícios e seu usufruto.

Os resultados apresentados, por constituírem conceitos sociais, não representam apenas os sujeitos da pesquisa, mas todos os trabalhadores que estão inseridos no mesmo contexto da organização capitalista. Tais significa- 
ções colhidas de trabalhadores podem se diferenciar em outras populações ou período em que seja realizado o estudo.

Assim, concluiu-se que o corpo, que deveria ser um meio utilizado para produção e realização de atividades prazerosas e construtivas objetiva e subjetivamente, está sendo obrigado cada dia mais - e por necessidades diversas - a se submeter a trabalhos desgastantes, que podem impedi-lo ou limitá-lo, pela doença, de realizar tarefas profissionais e pessoais.

\section{Colaboradores}

Alana Pires Dale foi responsável pela elaboração e redação do manuscrito, enquanto Maria Dionísia do Amaral Dias incumbiu-se da revisão crítica.

Resumen Entre las enfermedades profesionales con mayor prevalencia se encuentran las lesiones por esfuerzos repetitivos/enfermedades profesionales osteomusculares (LER-EPO), las cuales se relacionan directamente con la organización del trabajo que ignora los límites del cuerpo y las particularidades de los trabajadores. El objetivo principal del estudio que dio origen a este artículo fue investigar los significados del cuerpo en el trabajo, en individuos con este tipo de lesión/enfermedad. Para alcanzar el objetivo propuesto, se realizó un estudio de caso con enfoque cualitativo, fundamentado en la teoría socio-histórica de la psicología. Se utilizaron entrevistas abiertas individuales para la recolección de datos, realizadas con nueve participantes, los cuales tenían diagnóstico de lesiones por esfuerzos repetitivos/enfermedades profesionales osteomusculares y tenían seguimiento del Centro de Referencia en Salud del Trabajador de Botucatu (São Paulo, Brasil). El análisis de los datos reveló tres núcleos de significación: necesidad de trabajar — el cuerpo en movimiento; sumisión del cuerpo - falta de autonomía/poder; y cuerpo impedido - 'tuve un bloqueo, mi vida se detuvo'. En base a estos núcleos, se identificaron los significados y los elementos explicativos; El presentismo se destacó entre los significados encontrados. La expresión que mejor define todo el proceso salud-enfermedad de los participantes es 'la extravagancia de trabajar enfermo', y el producto de éste es un futuro incierto.

Palabras clave LER-EPO; significados del cuerpo; enfermedades profesionales; salud del trabajador; organización del trabajo. 


\title{
Notas
}

\author{
${ }^{1}$ Universidade Estadual Paulista, Faculdade de Medicina de Botucatu, Botucatu, São \\ Paulo, Brasil. \\ <alanapiresdale@yahoo.com.br> \\ Correspondência: Avenida São Paulo, 123, Santo Antônio, CEP 35770-000, Caetanópolis, \\ Minas Gerais, Brasil. \\ ${ }^{2}$ Universidade Estadual Paulista, Faculdade de Medicina de Botucatu, Departamento \\ de Saúde Coletiva e Programa de Pós-Graduação em Saúde Coletiva. \\ $<$ dionisia@fmb.unesp.br>
}

\section{Referências}

ALVES, Giovanni. Dimensão da precarização do trabalho: ensaios de sociologia do trabalho. Bauru: Editora Praxis, 2013.

AGUIAR, Wanda M. J.; OZELLA, Sergio. Núcleo de significação como instrumento para a apreensão da constituição dos sentidos. Psicologia: Ciência e Profissão, Brasília, v. 26, n. 2, p. 222-245, 2006. Disponível em: <http:// www.scielo.br/pdf/pcp/v26n2/v26n2a06.pdf>. Acesso em: 4 jan. 2017.

AGUIAR, Wanda M. J.; OZELLA, Sergio. Apreensão dos sentidos: aprimorando a proposta dos núcleos de significação. Revista Brasileira de Estudos Pedagógicos, Brasília, v. 94, n. 236, p. 299-322, 2013. Disponível em: <http:// rbep.inep.gov.br/index.php/RBEP/article/ viewFile/2271/1908>. Acesso em: 5 fev. 2015.

ANTUNES, Ricardo. Adeus ao trabalho: ensaio sobre as metamorfoses e a centralidade do mundo do trabalho. 16. ed. São Paulo: Cortez, 2015.

ARAÚJO, Jane P. Afastamento do trabalho: absenteísmo e presenteísmo em uma instituição federal de ensino superior. 2012. 122f. Dissertação (Mestrado em Ciências da Saúde) - Universidade de Brasília, Brasília, 2012.

ARAÚJO, José N. G. Qualidade de vida no trabalho: controle e escondimento do mal-estar do trabalhador. Trabalho, Educação e Saúde, Rio de Janeiro, v. 7, n. 3, p. 573-585, 2009. Disponível em: <http://www.scielo.br/pdf/ tes/v7n3/11.pdf>. Acesso em: 21 mar. 2014.
ASSUNÇÃO, Ada A.; ROCHA, Lys E. Agora... até namorar fica difícil: uma história de lesões por esforços repetitivos. In: BUSCHINELLI, José T. P.; ROCHA, Lys E.; RIGOTTO, Raquel M. (orgs.). Isto é trabalho de gente?: vida, doença e trabalho no Brasil. Petrópolis: Vozes, 1994. p. 461-493.

BARBOSA, Maria S. A.; SANTOS, Regina M.; TREZZA, Maria C. S. F. A vida do trabalhador antes e após a lesão por esforço repetitivo (LER) e doença osteomuscular relacionada ao trabalho (DORT). Revista Brasileira de Enfermagem, Brasília, v. 60, n. 5, p. 491-496, 2007. Disponível em: <http://www.scielo.br/ pdf/reben/v60n5/v60n5a02.pdf $>$. Acesso em: 8 maio 2013.

BRAGA, Juliana C. M. et al. Tensões no trabalho: estudo com operadores de caixa de uma rede mineira de supermercados. Revista Eletrônica de Administração, Porto Alegre, v. 12, n. 1, p. 15-30, 2013. Disponível em: <http:// periodicos.unifacef.com.br/index.php/rea/ article/view/476>. Acesso em: 8 mar. 2016.

BRASIL. Ministério da Saúde. Doenças relacionadas ao trabalho: manual de procedimentos para serviços de saúde. Brasília: Ministério da Saúde, 2001. Disponível em: <http:// bvsms.saude.gov.br/bvs/publicacoes/doencas_relacionadas_trabalhol.pdf $>$. Acesso em: 10 out. 2016.

BRASIL. Ministério da Saúde. Secretaria de Vigilância em Saúde. Departamento de Vigilância 
em Saúde Ambiental e Saúde do Trabalhador. Dor relacionada ao trabalho: lesões por esforços repetitivos (LER) - distúrbios osteomusculares relacionados ao trabalho (DORT). Brasília: Editora do Ministério da Saúde, 2012 (Série A. Normas e Manuais Técnicos) (Saúde do Trabalhador, 10. Protocolos de Complexidade Diferenciada). Disponível em: <http://www.pmf.sc.gov.br/ arquivos/arquivos/PDF/02_03_2012_10.47.50. 84dd22452d672be32f628a362dfadfbf.PDF>. Acesso em: 14 ago. 2014.

CASTELHANO Laura M. O medo do desemprego e a(s) nova(s) organizações de trabalho. Psicologia \& Sociedade, Porto Alegre, v. 17, n. 1, p. 17-28, 2005. Disponível em: <http:// www.scielo.br/pdf/psoc/v17nl/a03v17nl. pdf $>$. Acesso em: 18 dez. 2015.

CHIAVEGATO FILHO, Luiz G.; PEREIRA JUNIOR, Alfredo. LER/DORT: multifatorialidade etiológica e modelos explicativos. Interface: Comunicação, Saúde e Educação, Botucatu, v. 8, n. 14, p. 149-162, 2004. Disponível em: $<$ http://www.scielo.br/pdf/icse/v8n 14/ v8n14a08.pdf $>$. Acesso em: 12 mar. 2014.

DALE, Alana P. Significados do corpo no trabalho em indivíduos com diagnóstico de LER. 2015. 96f. Dissertação (Mestrado em Saúde Coletiva)Faculdade de Medicina, Universidade Estadual Paulista, Botucatu, 2015.

DIAS, Maria D. A. Saúde do trabalhador: uma questão de cidadania - estudo de caso com portadores de lesões por esforços repetitivos (LER). 139f. Dissertação (Mestrado em Psicologia Social) - Pontifícia Universidade Católica de São Paulo, São Paulo, 1995.

EUFRASIO, Karem N. Estratégias defensivas em gestores de uma empresa de contabilidade. $31 \mathrm{f}$. Trabalho de conclusão de curso (Especialização em Clínica psicodinâmica do trabalho e Gestão do estresse) - Instituto de Psicologia, Universidade de Brasília, Brasília, 2014.

FRANCO, Tânia; DRUCK, Graça; SELIGMANNSILVA, Edith. As novas relações de trabalho, o desgaste mental do trabalhador e os transtornos mentais no trabalho precarizado. Revista Brasileira de Saúde Ocupacional, São Paulo, v. 35 , n. 122 , p. $229-248,2010$. Disponível em: <http://www.scielo.br/pdf/rbso/v35nl22/ a06v35n122.pdf $>$. Acesso em: 10 set. 2014.

GAEDKE, Maria A.; KRUG, Suzane B. F. Quem eu sou? A identidade de trabalhadoras portadoras de LER/DORT. Textos \& Contextos, Porto Alegre, v. 7, n. 1, p. 120-137, 2008. Disponível em: <http://revistaseletronicas.pucrs.br/ ojs/index.php/fass/article/view/3942/3206>. Acesso em: 13 out. 2013.

GARROW, Valerie. Presenteeism: a review of current thinking. Institute for Employment Studies, Report 507, 2016. Disponível em: <http://www. employment-studies.co.uk/system/files/resources/files/507_0.pdf>. Acesso em: 5 dez. 2016.

HELLER, Agnes. O cotidiano e a história. 2. ed. São Paulo: Paz e Terra, 1985.

IRIART, Jorge A. B. et al. Representações do trabalho informal e dos riscos à saúde entre trabalhadoras domésticas e trabalhadores da construção civil. Ciência \& Saúde Coletiva, Rio de Janeiro, v. 13, n. 1, p. 165-174, 2008. Disponível em: <http://www.scielo.br/scielo.php?script=sci_ arttext\&pid $=$ S1413-81232008000100021 > Acesso em: 12 mar. 2016.

LAURELL Asa C.; NORIEGA Mariano. Processo de produção e saúde: trabalho e desgaste operário. São Paulo: Hucitec, 1989.

LEONTIEV, Alexis. O desenvolvimento do psiquismo. São Paulo: Moraes, 1978.

MOULIN, Maria G. B.; REIS, Cleison T.; WENICHI, Grace H. Homens de pedra? Pesquisando o processo de trabalho e saúde na extração e no beneficiamento do mármore - relato de uma experiência. Cadernos de Psicologia Social do Trabalho, São Paulo, v. 3/4, p. 47-63, 2001. Disponível em: <http://www.revistas.usp. br/cpst/article/view/25996>. Acesso em: 26 abr. 2015.

NEVES, Ilidio R. LER: trabalho, exclusão, dor, sofrimento e relação de gênero - um estudo com trabalhadoras atendidas num serviço público de saúde. Cadernos de Saúde Pública, Rio de Janeiro, v. 22, n. 6, p. 1.257-1.265, 
2006. Disponível em: <http://www.scielo.br/ scielo.php?script=sci_arttext\&pid=S0102311X2006000600015>. Acesso em: 25 abr. 2015.

OLIVEIRA, Paulo A. B.; MENDES, Jussara M. R. Processo de trabalho e condições de trabalho em frigoríficos de aves: relato de uma experiência de vigilância em saúde do trabalhador. Ciência \& Saúde Coletiva, Rio de Janeiro, v. 19, n. 12, p. 4.627-4.635, 2014. Disponível em: <http://www.scielo.br/pdf/ csc/v19n12/1413-8123-csc-19-12-04627.pdf>. Acesso em: 23 mar. 2015

PENA, Paulo G. L.; MINAYO-GOMEZ, Carlos. Premissas para a compreensão da saúde dos trabalhadores no setor de serviços. Saúde e Sociedade, São Paulo, v. 19, n. 2, p. 371-383, 2010. Disponível em: <http://www.scielo. br/pdf/sausoc/v19n2/13.pdf $>$. Acesso em: 4 dez. 2016.

PERO, Valéria. Grupos vulneráveis no mercado de trabalho brasileiro. Brasília: Senai, 2010 (Série Cenários, n. 4). Disponível em: <http:// tracegp.sesi.org.br/bitstream/uniepro/173/1/ Grupos_Vulneraveis_WEB.pdf $>$. Acesso em: 7 dez. 2016.

PESSOA, Juliana C. S.; CARDIA, Maria C. G.; SANTOS, Maria L. C. Análise das limitações, estratégias e perspectivas dos trabalhadores com LER/DORT, participantes do grupo ProfitLER: um estudo de caso. Ciência \& Saúde Coletiva, Rio de Janeiro, v. 15, n. 3, p. 821830, 2010. Disponível em: <http://dx.doi. org/10.1590/S1413-81232010000300025>. Acesso em: 23 set. 2013.

REGIS FILHO, Gilsée I.; MICHELS, Glaycon; SELL, Ingeborg. Lesões por esforços repetitivos/ distúrbios osteomusculares relacionados ao trabalho em cirurgiões-dentistas. Revista Brasileira de Epidemiologia, São Paulo, v. 9, n. 3, p. 346-359, 2006. Disponível em: <http:// dx.doi.org/10.1590/S1415-790X2006000300009>. Acesso em: 14 out. 2014.

ROCHA, Adelaide M.; FELLI, Vanda E. A. A saúde do trabalhador de enfermagem sob a ótica da gerência. Revista Brasileira de Enfermagem, Brasília, v. 57, n. 4, p. 453-458, 2004.
Disponível em: < http://www.scielo.br/pdf/ reben/v57n4/v57n4al3.pdf $>$. Acesso em: 12 maio 2015 .

ROSA, Aparecida F. G. et al. Incidência de LER/ DORT em trabalhadores de enfermagem. Acta Scientiarum Health Sciences, Maringá, v. 30, n. 1, p. 19-25, 2008. Disponível em: <http:// eduem.uem.br/ojs/index.php/ActaSciHealthSci/ article/viewArticle/4383>. Acesso em: 12 ago. 2013.

SILVA, Emília P. et al. Fatores organizacionais e psicossociais associados ao risco de LER/ DORT em operadores de máquinas de colheita florestal. Revista Árvore, Viçosa, v. 37, n. 5, p. 889-895, 2013. Disponível em: <http:// www.scielo.br/pdf/rarv/v37n5/11.pdf $>$. Acesso em: 6 dez. 2016.

SOARES, Érika L. A. Trabalho e precarização: breve análise sobre o recente cenário de adoecimento entre trabalhadores da construção civil. Revista da Abet, s.l., v. 12, n. 2, p. 48-62, 2013. Disponível em: <http://periodicos.ufpb. br/index.php/abet/article/view/20207/11214>. Acesso em: 27 abr. 2015.

SOUZA, Maria E. L.; FAIMAN, Carla J. S. Trabalho, saúde e identidade: repercussões do retorno ao trabalho, após afastamento por doença ou acidente, na identidade profissional. Saúde, Ética e Justiça, São Paulo, v. 12, n. 1/2, p. 22-32, 2007. Disponível em: <http://www. revistas.usp.br/sej/article/view/44356/47977>. Acesso em: 7 dez. 2016.

SZNELWAR, Laerte I.; MASSETTI, Morgana. Agressões ao corpo e/ou sofrimento psíquico? Um estudo construído a partir da experiência de trabalhadores com LER/ DORT. Travailler, s.1., n. 8, p. 153-176, 2002. Disponível em: <http://www.cairn. info/revue-travailler-2002-2-page-153.htm >. Acesso em: 30 abr. 2015.

TAKAHASHI, Mara A. B. C. et al. Precarização do trabalho e risco de acidentes na construção civil: um estudo com base na análise coletiva do trabalho (ACT). Saúde e Sociedade, São Paulo, v. 21, n. 4, p. 976-988, 2012. Disponível em: $<$ http://www.scielo.br/scielo.php?pid=S0104- 
$12902012000400015 \&$ script $=$ sci_arttext $>$. Acesso em: 26 abr. 2015.

TORRES, Amélia R. A. et al. O adoecimento no trabalho: repercussões na vida do trabalhador e de sua família. Sanare, Sobral, v. 10, n. 1, p. 42-48, jan.-jun. 2011. Disponível em: <https://sanare.emnuvens.com.br/sanare/ article/view/142>. Acesso em: 4 dez. 2016.

Recebido em 16/05/2016.

Aprovado em 25/06/2017. 